\title{
Erratum to: The biology of cancer-related fatigue: a review of the literature
}

\author{
Leorey N. Saligan ${ }^{1} \cdot$ Karin Olson ${ }^{2} \cdot$ Kristin Filler $^{1} \cdot$ David Larkin $^{3} \cdot$ Fiona Cramp $^{4}$. \\ Sriram Yennurajalingam ${ }^{5}$ - Carmen P. Escalante ${ }^{5}$ - Auro del Giglio ${ }^{6} \cdot$ Kord M. Kober $^{7}$. \\ Jayesh Kamath $^{8}$ - Oxana Palesh ${ }^{9} \cdot$ Karen Mustian $^{10}$ • Multinational Association of \\ Supportive Care in Cancer Fatigue StudyGroup-Biomarker Working Group
}

Published online: 17 June 2015

(C) Springer-Verlag Berlin Heidelberg 2015

\section{Erratum to: Support Care Cancer}

\section{DOI 10.1007/s00520-015-2763-0}

The original version of this paper unfortunately mis-spelled the name of Sriram Yennurajalingam and it is now corrected in the authorgroup of this article.

The online version of the original article can be found at http://dx.doi.org/ $10.1007 / \mathrm{s} 00520-015-2763-0$.

Leorey N. Saligan

saliganl@mail.nih.gov

1 National Institute of Nursing Research, National Institutes of Health, 9000 Rockville Pike, Building 3, Room 5E14, Bethesda, MD 20892, USA

2 Faculty of Nursing, University of Alberta, Edmonton, Canada

3 Australian Capital Territory Health, University of Canberra, Canberra, Australia

4 University of the West of England, Bristol, UK
5 University of Texas MD Anderson Cancer Center, Houston, TX, USA

6 Brazilian Albert Einstein Jewish Hospital, Sao Paulo, Brazil

7 Department of Physiological Nursing, University of California, SanFrancisco, CA, USA

8 University of Connecticut Health Center, Farmington, CT, USA

9 Psychiatry and Behavioral Sciences, Stanford University Medical Center, Stanford, CA, USA

10 Wilmot Cancer Institute, University of Rochester Medical Center, Rochester, NY, USA 